\title{
Authorship and Anonymity in Experimental Design: Museum of the Ordinary and Museum Guixé
}

Individual creativity is a celebrated attribute of well-known designers. Undoubtedly the attention lavished on particular star designers by consumers and the media has evolved from design exhibitions reminiscent of those in fine art museums. An alternative to the celebration of designers as quasi-artists in exhibition contexts is to draw attention to designs by unnamed and anonymous practitioners. I argue that the paradigms of authored and anonymous design since the 1990 s echo the debates at the Deutscher Werkbund in 1914 and in the 1950 and 6 os at the Hochschule für Gestaltung (HfG), Ulm. Against the background of these divided definitions of design, the paper analyses Museum of the Ordinary by Michael Rock, Susan Sellers and Georgianna Stout (1998), a project that drew out design's situated meaning by transposing the institutional markers of museums to the street, and Museum Guixé by Marti Guixé (2007) which transposed the street to the museum in a design retrospective presented as a hawker's market. Since both projects registered the trend for exhibiting design as artworks in museums and can be linked to the celebration of the designer as artist or brand the paper concludes that they represent a productive tension between authorship and anonymity as competing definitions of design. I argue that these divided definitions of design maintain the complexities of the field and mitigate reductive positions in design discourse. design authorship, anonymous design, experimental design, Museum of the Ordinary, Museum Guixé

\section{Introduction}

\section{Approaches to design at the Werkbund and HfG, Ulm}

The recent reprisal of debates around authored experimental design versus anonymous design lends a contemporary critique of design practice to design history. This critique is concerned with the worldviews that shape the design exhibitions discussed in this paper and reflect the competing paradigms of design debated at a conference on the principles of design at the Deutscher Werkbund in 1914. At this conference, Hermann Muthesius insisted that design focus on the standardization of type-forms for mass manufacture.

Countered by Henry Van de Velde's proposition that design was the product of individual artists (Schwartz 1996), these different positions at the Deutscher Werkbund (1907-1938) set the scene for ongoing debates about anonymous versus authored design. Recycled at the Bauhaus as a discourse on artistic production, function, economy and standardization for industrial manufacture (1919-1933), the debate was elaborated at the HfG, Ulm, where design was theorized within a broader framework informed by economics, science and 
technology (1953-1968). The unresolved tension between anonymous design produced for an industrial economy and the valorisation of authored design and originality, as it is characterised today, keeps design's definitional contradictions in play.

The models of design debated at Ulm covered the gamut of universal form, branded product, and authored design critique and prescribed the roles available to designers as industrial engineer and social provocateur. Expressed in slogans such as "No more Art, the Street [is] more important than the Museum" (Aicher cited in Jacob 1988: 231), Ulm redefined industrial and visual communication design as socially embedded practices that remade design as an "engaged consumer science" (Betts 2004: 177). Under Tomás Maldonado's direction (1955-1964) Ulm collaborated with manufacturers in partnerships that contributed to the cultural reformation of Germany after WWII. Ulm's formulation of design as an integration of analysis, materials and use in a methodical, systematized, process for mass production was developed with companies such as Braun. After replacing the Bauhaus definition of design as an applied art and recognizing the coercive implications of designers collaborating with industry, Maldonado and Gui Bonsiepe modified the school's philosophy and reasserted UIm's agenda of social reform by insisting that designers assume an "active criticism" of the implications of design's cultural, economic and technological effects when partnering with industry (Bonsiepe 1999: 124). Rather than critique at a distance, this meant intervention through "design actions" engaged with industry (Bonsiepe 1999: 126). I contend that it is Ulm's commitment to defining design as operational critique that returns in some recent experimental design exhibitions.

Informed by tensions between the agency of designers and a commitment to the distribution of functional and cheap mass manufactured design, design historian Guy Julier and designer and critic Michael Rock opposed experimental authored design of the 1990s. They argued that when design borrows ideas and values from fine art, it is integrated into art-historical models that obfuscate the specifics of design practice. Julier saw the recasting of designers as artists in authored design as merely advertising the designer's brand and increasing their stock-value via institutional acceptance in art museum collections. He criticised the focus on formal over functional values in experimental design as a "simulacrum of risk" or individualistic cultural transgression that targeted consumers in the market for luxury goods (Julier 2008: 88). The exceptions he contended, were the Italian radical design groups of Alchymia and Memphis which he saw as disrupting the conventions of luxury design. Julier's celebration of the 1960 as a period of legitimate design critique of the status quo cast more recent experimental design as merely complicit with consumerism and devoid of social critique.

Particularly influential was Rock's analysis of the implications of transplanting avantgardist transgression from art to design in authored experimental typography in Fuse and Émigré magazines (Rock 1994, 1996). Echoing Ulm's commitment to social reform, Rock contended that because of its absolute social and pragmatic function design is inevitably imbricated in service-oriented relationships with clients. He argued it was therefore nonsensical to evaluate design within the same theoretical and historical frameworks as artistic practice, given the differences between the histories and purposes of fine art and design. Rock's observations were based on his rejection of the assumption that "authored design holds some higher, purer purpose" (Rock 1998: 53). 


\section{Exhibiting anonymous design: Museum of the Ordinary (1998)}

In the midst of the authorship debates Rock and collaborators from Studio $2 \times 4$ promoted an exhibition of anonymous and situated design that refused the framing of designers as artists or authors. Titled Museum of the Ordinary (M.O.) (1998), the project was presented as a museum in situ on the streets of Manhattan. The contracted title M.O., defined as modus operandi, set the tone for the practical critique that the project made about the methods of museums that strip design of its everyday function (Rock and Sellers 2013: 367). M.O.'s collection, comprising artefacts in an area in SoHo, reversed the effects of museums that frame a design as "an autonomous object" when exhibited as an artwork (Rock and Sellers 1998a: 144). Reflecting the concerns of Ulm, M.O. proposed to project historical statements about the use and abandonment of various sites onto building facades. M.O. marked out the anonymous designs of a fire hydrant and a bank of billposters with authoritative labels and a red velvet rope (Fig. 1-2). Parodying how design has come to be exhibited in art museums, the label for the fire hydrant followed museological conventions, listing product name, manufacturer, date and a brief description
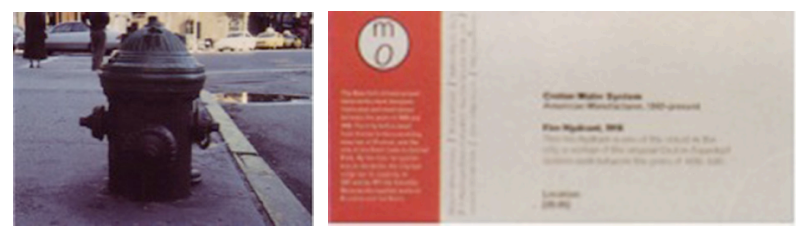

Figure 1.

Michael Rock, Susan Sellers and Georgianna Stout (1998), Museum of the Ordinary, detail.

Paradoxically M.O. took to the street the very museumification of design that elevated the individual designer to star status. The anonymous designs would in fact disappear into the street unless marked by museum labels. Yet M.O. has only been discussed in terms of anonymous rather than experimental design. After its publication in Design beyond Design and Eye magazine the project was exhibited at Artists Space in New York in 2001. Publicising information about ownership, value, and use of objects and buildings, M.O. drew attention to the everyday context and experience of design. The project showed that when anonymous design is removed from its context and exhibited in a museum it loses its functional value. In sum, M.O. framed the anonymous design found in downtown Manhattan as worthy of the contemplation with which authored design exhibited as artworks in museums encourages. Rather than strip the design object of meaning through a parody of display, M.O. amplified design's everyday functions by drawing attention to its context of use. The project underscored Rock's definition of design as a process of handling or manipulating content rather than its creation. In his words, "the language of the designer is a language about treatment and it is in treatment that [we] create, and not through content per se" (2005: np).

\section{Tensions between anonymous and authored design: Museum Guixé (2007)}

In contrast to M.O., Museum Guixé was framed as a "new type of cross-breed" of art and design when shown in an exhibition of artists and designers 'Wouldn't it be Nice... Wishful Thinking in Art and Design' (Garcia-Antón, King, Brändle 2007: 33). As a mini-retrospective of Guixé's commercial commissions, experimental designs and giftware, Museum Guixé was arranged on four, large cloths under fluorescent lights (Fig. 3). The cloths laid unceremoniously on the floor imported into the museum hawkers' blankets with which illegal merchandise is displayed and quickly bundled up to escape police when 
theme 3

identity

Figure 2.

Martí Guixé (2007), Museum Guixé, detail. strand 3

authorship and anonymous design

necessary. Each cloth was embroidered in Guixé's distinctive typography with the generic names Exhibition Hall 1, Exhibition Hall 2, Gift Shop and Book Shop. The inscriptions on the blankets and the title were the only clues that Guixé conceived the work as a museum. Unlike traditional design exhibitions there were no spotlights, plinths or protective barriers.

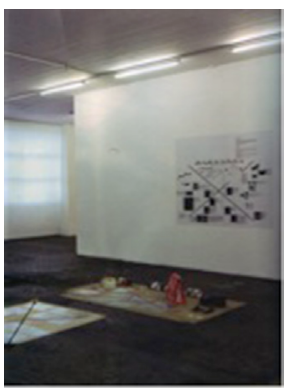

The retrospective of Guixé's branding designs (shopping bags, give-aways and interior designs) for shoe manufacturer Camper, a company whose designers remain anonymous, was exhibited beside commercial giftware branded with his name. Given the ubiquity of Guixé's giftware for sale in museum stores throughout Europe, the arrangement of the designs raised questions about the mismatch of authorship and anonymity in exhibiting design as art. As M.O. foregrounded anonymity and the context specificity of design's function by reframing found designs with the tropes of museum exhibitions, Museum Guixé promoted authorship in a 'museum' titled with the designer's name. The contradiction in Guixé's museum is that it promoted his work as a brand at the same time as demonstrating the Ulmian ethos of operational critique.

This aspect of Museum Guixé was most evident in the two exhibition halls. Guixé's acerbic comments on design's function and meaning featured on a shopping bag printed with the slogan "If you don't need it, don't buy it" designed for Camper (2002-2003), displayed near Autoband (1999) a tape printed with anonymously designed road markings along which children can lay out paths for toy cars. Photographs of Camper store interiors designed by Guixé were exhibited beside the instruction cards with which he provided design specifications for construction in various capital cities. In layouts reminiscent of Ikea's DIY instruction sheets for furniture assemblage Guixé's Camper cards recycled Ulm's emphasis on modularity, standardisation and anonymous design. Guixé's preference for Ikea as a model for design exhibitions, because the company allows visitors to "touch, try or buy", challenged the display of one-off luxury brand designs by celebrity designers (Guixé cited in Garcia-Anton et al 2007: 255). This approach revived key aspects of the Ulmian definition of design as a democratising process of social reform and the principle of active intervention. Guixé's museum recalled Ulm's idea of design as affordable and widely available and their view of the designer as intervening in the manufacture and retailing of design to this end. In replaying the reformist agenda of Ulm while highlighting his name as an author-designer in brand design, Museum Guixé expressed the doubleedged nature of design: the role of the designer as both agent provocateur engaged in operational critique and as imbricated in the demands of industrial production of consumer goods. 


\section{The critical value of maintaining the tensions between anonymous and authored design}

The historically contested understandings of design as standardized and anonymous type-forms or artistically and individually authored brands since the Deutscher Werkbund conference in 1914 were outlined in this paper. These competing definitions of design resurfaced at Ulm in the 50 and 6os, the design authorship debates in the 1990s, and discourses surrounding critical, social and experimental design in the 2000 s. At first glance, the experimental design exhibitions discussed here challenge certain orthodoxies. These include exhibiting design as authored creations and engaging with unresolved and divided positions on anonymity and authorship. While M.O. ascribed value to anonymity in design and Museum Guixé recycled Ulm's operational critique, they both reveal aspects of productive tensions between anonymous and authored design. The tensions generated through these divided understandings not only maintain the complexity of design but also check the tendency to simplify and reduce the purpose of design to the domain of the practical and pragmatic when it is involved in reflective, social and critical action. A second look reveals that these two projects are ambiguous, situated in a historical context saturated with branded design that celebrates the epitome of individual creativity. That is, both were exhibited as authored designs that directly or indirectly promulgated the designers' brands. Given the recent intensification of branding, this analysis opens definitional debates about design to include reflexive, critical and experimental practice that expand future possibilities for design scholarship.

\section{References}

Aicher, O. 'HfG Ulm: A Concise History', Archethese, 15 (1975). Reprinted as Appendix 3 in Heiner Jacob, 'HfG Ulm: A Personal View of an Experiment in Democracy and Design Education', Journal of Design History, Vol. 1, Nos. 3-4 (1988): 221-234.

Betts, P. (2004) The Authority of Everyday Objects: A Cultural History of West German Industrial Design, Berkeley: University of California.

Bonsiepe, G. (1999) Interface: An Approach to Design, Maastricht: Jan van Eyck Akademie. Fezer, J. (2008) 'Planning and Democracy: An interview with Tomás Maldonado', trans. Gerrit Jackson, Texte zur Kunst, No. 72, 109-114.

Garcia-Antón, K., King, E., and Brändle, C. (ed.s) (2007) Wouldn't It Be Nice ..Wishful Thinking in Art and Design, Geneva: Centre d'Art Contemporain Genève.

Julier, G. (2008) The Culture of Design, 2nd edition, London: Sage.

Rock, M. (1994) 'Beyond Typography', Eye: The International Review of Graphic Design, Vol. 4, No. 15, pp. 26-35.

Rock, M. (1996) 'The Designer as Author', Eye: The International Review of Graphic Design, Vol. 5, No. 20, pp. 44-53.

Rock, M. (2005) Interview with the author, New York, 5 October 2005.

Rock, M., and Sellers, S. (1998a) 'The Museum of the Ordinary' in Jan Van Toorn (ed.) Design beyond Design: Critical Reflection and the Practice of Visual Communication, Maastricht: Jan van Eyck Akademie Edition, pp. 133-147.

Rock, M., and Sellers, S. (1998b) 'The Museum of the Ordinary', Eye: The International Review of Graphic Design, Vol. 7, No. 28, Summer, pp. 32-35.

Rock, M., and Sellers, S. (2013) 'A Proposal for the Museum of the Ordinary', Multiple Signatures: On Designers, Authors, Readers and Users, New York: Rizzoli, pp. 367-270. Schwartz, F.J. (1996) The Werkbund. Design Theory and Mass Culture before the First World War, New Haven: Yale University Press. 
